\title{
Conservação pós-colheita de mangas 'Tommy Atkins' armazenadas sob atmosfera modificada
}

\section{Post harvest conservation of mangos 'Tommy Atkins' storaged under modified atmosphere}

\author{
Elisangela Marques Jeronimo ${ }^{1 *}$; Maria Amália Brunini²; Maria Cecília de Arruda3; \\ Juliana Cristina Sodário Cruz ${ }^{4}$; Ivan Herman Fischer ${ }^{5}$; Glauber José de Castro Gava ${ }^{6}$
}

\section{Resumo}

O presente trabalho objetivou avaliar a conservação pós-colheita de mangas 'Tommy Atkins', durante o armazenamento em condições de temperatura ambiente, utilizando diferentes tipos de embalagens. Os tratamentos foram: frutos acondicionados individualmente em bandejas de acetato transparente, revestidas com filme plástico de cloreto de polivinila (PVC esticável) de $14 \mu \mathrm{m}$, sem e com sachê de permanganato de potássio, preparado utilizando-se vermiculita como substrato, impregnada com $\mathrm{KMnO}_{4}(10 \mathrm{~g} / 500 \mathrm{~g}$ de fruto); frutos acondicionados individualmente em sacos plásticos de polietileno de baixa densidade $25 \mu \mathrm{m}$ de parede simples (PE) confeccionado ou não com permanganato de potássio e frutos acondicionados, em grupos de 5 , em caixas de papelão com tampa, revestidas internamente ou não, com filme plástico confeccionado com permanganato de potássio. Os frutos foram armazenados a temperatura ambiente média de $24,4{ }^{\circ} \mathrm{C}, 70 \% \mathrm{UR}$. Foram avaliadas a perda de massa fresca, aparência, firmeza da polpa, teor de sólidos solúveis, acidez titulável e ácido ascórbico. Verificou-se que os melhores tratamentos de atmosfera modificada foram os de acondicionamento individual dos frutos de manga em bandejas de acetato transparentes, recoberta com o filme de PVC esticável, com ou sem permanganato de potássio (BA e BAP), pois contribuíram para prolongar a conservação dos frutos em 4 dias, em relação ao controle (sem embalagem), em condições de temperatura ambiente (média de $24,4^{\circ} \mathrm{C}$ ). O permanganato de potássio na forma utilizada neste estudo (sachê preparado utilizando-se vermiculita como substrato, impregnada com $\mathrm{KMnO}_{4}$, na proporção de $10 \mathrm{~g} / 500 \mathrm{~g}$ de fruto e impregnado em filme plástico) não interferiu nos resultados obtidos para a conservação dos frutos.

Palavras-chave: Mangifera indica L, embalagem, qualidade

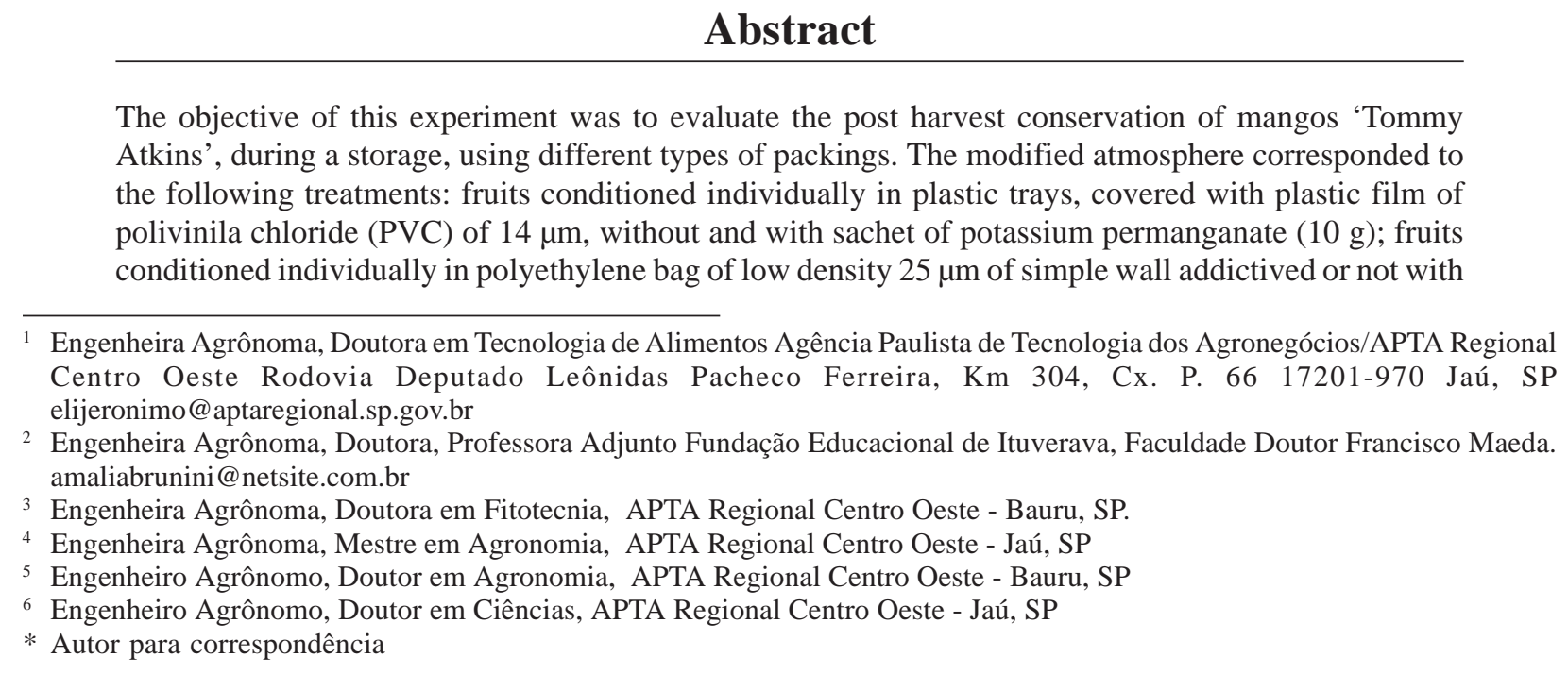

Abstract

The objective of this experiment was to evaluate the post harvest conservation of mangos 'Tommy Atkins', during a storage, using different types of packings. The modified atmosphere corresponded to the following treatments: fruits conditioned individually in plastic trays, covered with plastic film of polivinila chloride (PVC) of $14 \mu \mathrm{m}$, without and with sachet of potassium permanganate $(10 \mathrm{~g})$; fruits conditioned individually in polyethylene bag of low density $25 \mu \mathrm{m}$ of simple wall addictived or not with

\footnotetext{
1 Engenheira Agrônoma, Doutora em Tecnologia de Alimentos Agência Paulista de Tecnologia dos Agronegócios/APTA Regional Centro Oeste Rodovia Deputado Leônidas Pacheco Ferreira, Km 304, Cx. P. 66 17201-970 Jaú, SP elijeronimo@aptaregional.sp.gov.br

2 Engenheira Agrônoma, Doutora, Professora Adjunto Fundação Educacional de Ituverava, Faculdade Doutor Francisco Maeda. amaliabrunini@netsite.com.br

3 Engenheira Agrônoma, Doutora em Fitotecnia, APTA Regional Centro Oeste - Bauru, SP.

4 Engenheira Agrônoma, Mestre em Agronomia, APTA Regional Centro Oeste - Jaú, SP

5 Engenheiro Agrônomo, Doutor em Agronomia, APTA Regional Centro Oeste - Bauru, SP

6 Engenheiro Agrônomo, Doutor em Ciências, APTA Regional Centro Oeste - Jaú, SP

* Autor para correspondência
} 
potassium permanganate; conditioned fruits, in groups of 5, in carton boxes with cover, covered internally or no with low density polyethylene film addictived with potassium permanganate. The fruits were stored under storage room at $24,4{ }^{\circ} \mathrm{C}, 70 \% \mathrm{RH}$. The evaluated variables were: loss of fresh mass, appearance, firmness of the pulp, soluble solids, titratable acidity and ascorbic acid. It were verified that the best treatments of modified atmosphere were individual packaging of the mango fruits in plastic trays, covered with plastic film of polivinila chloride (PVC) of $14 \mu \mathrm{m}$, without and with sachet of potassium permanganate. The potassium permanganate, in the form used in this study (sachet and impregnated in plastic film), did not interfere in the results obtained for the conservation of the fruits.

Key words: Mangifera indica L, package, quality

\section{Introdução}

O Brasil é o sétimo maior produtor mundial e São Paulo o segundo maior Estado produtor nacional de manga (AGRIANUAL, 2005). Atualmente, uma das cultivares mais plantada é a 'Tommy Atkins', que apresenta características de sazonalidade bastante específicas, marcadas pela concentração da oferta no período de outubro a janeiro e de escassez entre fevereiro a setembro. A adoção de técnicas de pós-colheita com a finalidade de propiciar oferta no período de melhores preços torna-se necessárias (BRASIL, 1998).

No armazenamento sob atmosfera modificada (AM), a atmosfera do ambiente é alterada pelo uso de filmes plásticos ou recobrimentos comestíveis, permitindo que a concentração de $\mathrm{CO}_{2}$ aumente e a de $\mathrm{O}_{2}$ diminua decorrente da respiração do fruto. Neste sistema, as concentrações dos gases não são controladas, variando com o tempo, temperatura, permeabilidade do filme e atividade respiratória do produto. O filme plástico deve apresentar permeabilidade seletiva adequada à entrada de $\mathrm{O}_{2} \mathrm{e}$ saída de $\mathrm{CO}_{2}$, de modo que o produto não entre em anaerobiose ou processo de fermentação (CHITARRA; CHITARRA, 2005).

Cia (2002) descreve que a habilidade para regular a atmosfera estabelecida na embalagem dependerá da respiração do fruto e da permeabilidade da embalagem. Esses fatores, por sua vez, são dependentes da temperatura, já que a elevação da mesma promove aumento da atividade respiratória dos produtos e da permeabilidade do filme utilizado. Segundo esta mesma autora, com a utilização de filmes no acondicionamento dos frutos, verifica-se melhor apresentação do produto, eliminação ou redução do uso de fungicidas, redução da superfície de abrasão, diminuição do contato do fruto na sua comercialização, diminuição da contaminação do fruto durante o manuseio, manutenção de alta umidade relativa e redução da perda de massa.

Kluge e Jorge (1992) demonstraram que o uso de embalagem, principalmente de filme de polietileno, reduz drasticamente as perdas de massa de frutos e hortaliças, tanto no armazenamento, quanto na comercialização. Outros trabalhos de pesquisa também têm comprovado a eficácia do uso de embalagem de polietileno (PFAFFENBACH et al., 2003; BRUNINI et al., 2004; LIMA et al., 2005), como também de PVC (YAMASHITA et al., 2001).

O etileno é um composto liberado durante o metabolismo das frutas, que estimula a maturação, o amadurecimento e a senescência. Uma vez maduras, as frutas se deterioram rapidamente e o controle dos níveis de etileno pode prolongar a vida-de-prateleira (LABUZA; BREENE, 1989). Isso é feito geralmente por meio de remoção do etileno por algum agente oxidante, como por exemplo, o permanganato de potássio, geralmente incorporado ao sistema na forma de sachês com alta permeabilidade ao etileno, ou adicionado diretamente ao material de embalagem (ZAGORY, 1995).

A utilização de embalagens fabricadas com permanganato de potássio, ou o uso de sachê de permanganato de potássio no interior das embalagens, também tem sido estudado com a finalidade de absorver o etileno produzido pelos frutos durante os processos de amadurecimento (JERONIMO; KANESIRO, 2000; PFAFFENBACH et al., 2003). Awad (1993) descreve que é possível utilizar sachês de vermiculita impregnados com permanganato de potássio, para absorver e oxidar o etileno durante o armazenamento de frutos. 
Diante disso, o objetivo deste trabalho foi avaliar a conservação pós-colheita de mangas 'Tommy Atkins' em relação à aparência e às características físico-químicas, utilizando diferentes tipos de embalagens, armazenadas sem o uso de refrigeração.

\section{Material e Métodos}

Mangas 'Tommy Atkins' foram colhidas no estádio de maturação pré-climatérico, em pomar comercial em Cândido Rodrigues - SP e transportadas imediatamente para o Laboratório de Tecnologia dos Produtos Agrícolas do Departamento de Tecnologia da Faculdade de Ciências Agrárias e Veterinárias - UNESP - Jaboticabal - SP. Os frutos foram lavados em água potável contendo hipoclorito de sódio $\left(10 \mathrm{mg} \mathrm{L}^{-1}\right)$ e tratados por imersão em água quente $\left(55^{\circ} \mathrm{C}\right)$ durante 5 minutos, para desinfecção, e secos ao ar.

Na sequência, os frutos foram divididos em 7 grupos e submetidos aos seguintes tratamentos: frutos sem embalagem, que correspondeu ao grupo controle (SE); frutos acondicionados individualmente em bandejas de acetato transparente $(16 \mathrm{~cm}$ x $10 \mathrm{~cm} \mathrm{x}$ $6 \mathrm{~cm})$, revestidas com filme plástico de cloreto de polivinila (PVC esticável) $14 \mu \mathrm{m}$ (BA); frutos acondicionados individualmente em bandeja de acetato transparente $(16 \mathrm{~cm} \times 10 \mathrm{~cm} \times 6 \mathrm{~cm})$, revestidas com filme plástico de cloreto de polivinila de $14 \mu \mathrm{m}$ de espessura, contendo em seu interior sache (costurados artesanalmente, com material de tecido não tecido, de $4 \mathrm{~cm} \times 5 \mathrm{~cm}$ ) de permanganato de potássio ( $10 \mathrm{~g} / 500 \mathrm{~g}$ de fruto), preparado em laboratório, utilizando-se vermiculita como substrato impregnada com $\mathrm{KMnO}_{4}$ (BAP); frutos acondicionados individualmente em saco de polietileno de baixa densidade com $25 \mu \mathrm{m}$ de espessura (SP); frutos acondicionados individualmente em saco de polietileno de baixa densidade confeccionado com permanganato de potássio (SPP); frutos acondicionados, em grupos de 5, em caixas de papelão (35 cm x $25 \mathrm{~cm} \times 10 \mathrm{~cm}$ ), com tampa e 3 furos em cada lateral (CP); frutos acondicionados, em grupos de 5, em caixas de papelão ( $35 \mathrm{~cm}$ x $25 \mathrm{~cm}$ x $10 \mathrm{~cm})$, com tampa e 3 furos em cada lateral, revestidas internamente com filme polietileno de baixa densidade confeccionado com permanganato de potássio (CPP). A temperatura de armazenamento média foi de $24,4{ }^{\circ} \mathrm{C}$, com umidade relativa média de $70 \%$, durante todo o período de conservação dos frutos, isto é, até a perda do valor comercial.

A qualidade dos frutos foi avaliada pelas variáveis: perda de massa fresca, aparência, firmeza da polpa, teor de sólidos solúveis, acidez titulável e ácido ascórbico. A perda de massa fresca foi determinada pela diferença entre a massa fresca inicial das unidades experimentais e a massa final após cada período de armazenamento e expressa em porcentagem. A aparência foi determinada por método subjetivo utilizando-se uma escala de notas, onde: 1 = bom; 2 = regular; 3 = ruim. A firmeza da polpa foi determinada com penetrômetro manual Bishop FT 327, ponteira $8 \mathrm{~mm}$, e os resultados expressos em Kgf.cm ${ }^{-2}$.

Os teores de sólidos solúveis foram determinados por refratometria e expressos em ${ }^{\circ}$ Brix, a acidez titulável, foi determinada por titulação e os resultados expressos em \% de ácido cítrico e os teores de ácido ascórbico pelo método do dicloroindofenol de sódio (2,6 dicloroindofenol de sódio). (INSTITUTO ADOLFO LUTZ, 1985) e os resultados expressos em mg. $100 \mathrm{~g}^{-1}$. O "ratio" foi calculado pela relação entre o teor de sólidos solúveis e acidez.

O delineamento experimental utilizado foi $\mathrm{o}$ inteiramente casualizado, com duas repetições. As médias dos resultados obtidos foram comparadas pelo teste de Tukey ao nível de 5\% de probabilidade (BANZATTO; KRONKA, 1995).

\section{Resultados e Discussão}

Nos frutos não embalados (SE), a perda de massa fresca foi $14,91 \%$ ao final do armazenamento (Figura 1). Com a utilização de atmosfera modificada, as perdas de massa fresca foram reduzidas para $1,13 \%$ no 
tratamento SP, 0,86\% em SPP, 4,64\% em BA, 4,62\% em BAP, $8,33 \%$ em CP e 9,12\% em CPP. Todos os frutos submetidos ao acondicionamento em embalagens diferiram estatisticamente do controle (SE).

Os tratamentos BA, BAP, SP e SPP foram mais efetivos em relação à redução de perda de massa fresca. A redução da perda de matéria fresca dos frutos foi devido à atmosfera modificada pelo uso da embalagem (baixa permeabilidade dos filmes ao vapor de água). O mesmo efeito foi verificado por Souza et al.(2002) em estudo de armazenamento de mangas em atmosfera modificada por filmes plásticos.
O uso do permanganato de potássio nas embalagens, na forma de sache, não apresentou diferenças na redução da perda de massa dos frutos, em relação aos frutos que foram acondicionados em embalagens sem o sache de permanganato de potássio (Figura 1), mostrando que no tratamento BAP houve apenas o efeito da permeabilidade da embalagem ao vapor de água. Esta observação é contrária ao relatado por Wavhal e Athale (1989), que constataram redução na perda de massa de mangas acondicionadas em sacos de polietileno contendo sachê de permanganato de potássio.

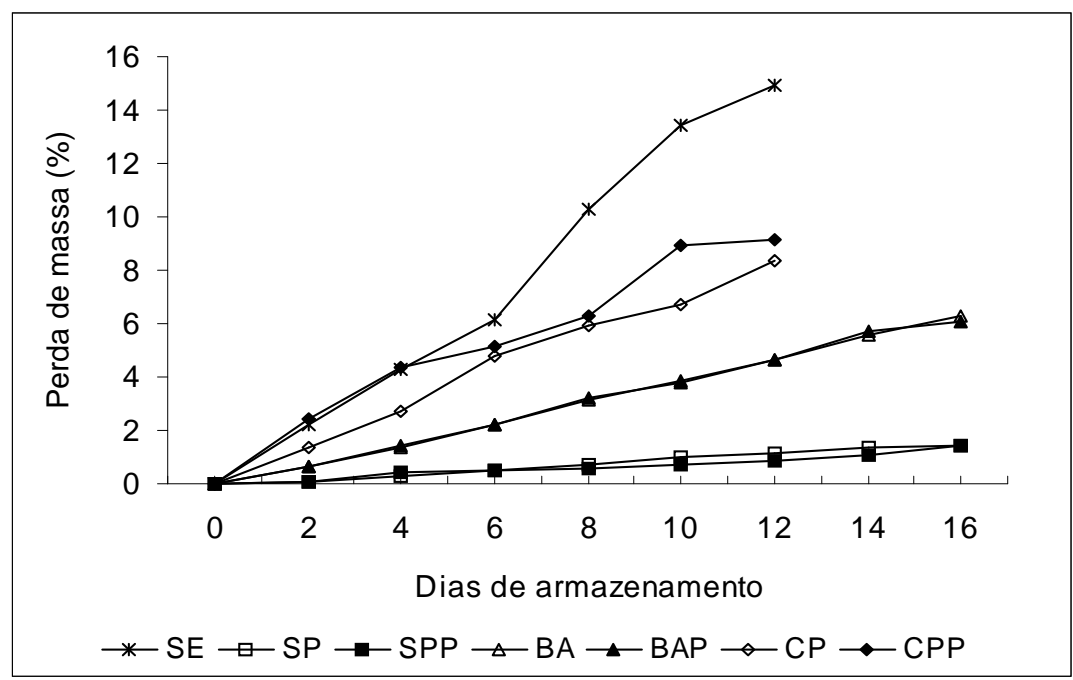

Figura 1. Perda de massa fresca em mangas 'Tommy Atkins', durante armazenamento a $24,4{ }^{\circ} \mathrm{C}, 70 \% \mathrm{UR}$ SE $=$ frutos sem embalagem; $\mathrm{SP}=$ frutos acondicionados, individualmente, em saco plástico de polietileno; $\mathrm{SPP}=$ frutos acondicionados, individualmente, em saco plástico confeccionado com permanganato de potássio; BA= frutos acondicionados, individualmente, em bandeja de acetato; $\mathrm{BAP}=$ frutos acondicionados, individualmente, em bandeja de acetato transparente, contendo em seu interior sachê de permanganato de potássio; $\mathrm{CP}=$ frutos acondicionados em caixas de papelão, em grupos de 5; $\mathrm{CPP}=$ frutos acondicionados em caixas de papelão, em grupos de 5 , revestidas internamente com filme plástico aditivado com permanganato de potássio.

A aparência externa é fundamental em frutos destinados ao mercado in natura, por ser fator de atratividade e exercer influência direta sobre a escolha do consumidor. No caso de mangas, estas devem apresentar a casca limpa, firme, livre de machas e de rugosidade. Neste trabalho, a nota "2" foi associada à aparência regular e aceitável para o consumo, isto é, considerada como um valor determinante para a vida comercial destes frutos. Os frutos sem embalagem (SE) mantiveram aparência boa e regular por 12 dias. Os frutos acondicionados em bandejas de acetato, sem e com sachê de permanganato de potássio (BA e BAP), apresentaram aspecto aceitável para consumo por 16 dias e os acondicionados em sacos plásticos (SP e SPP) por 14 dias. Os frutos acondicionados em caixa de papelão (CP e CPP) mantiveram a aparência boa e regular por até 12 dias (Figura 2). A presença do permanganato de potássio não mostrou resultados relevantes na manutenção da aparência dos frutos avaliados no presente estudo. 


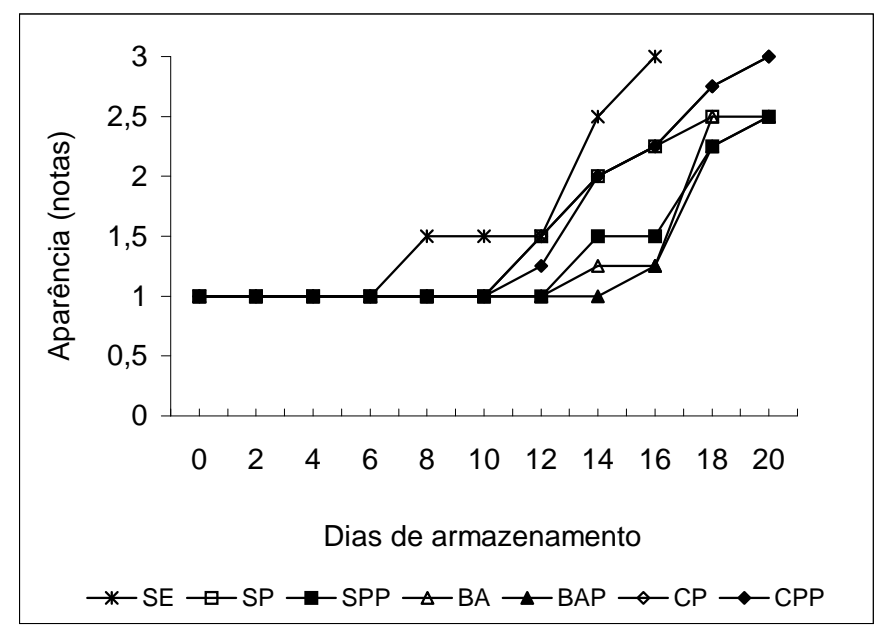

Figura 2. Nota* de Aparência de mangas ‘Tommy Atkins', durante armazenamento a $24,4{ }^{\circ} \mathrm{C}, 70 \%$ UR . * $1=$ bom; $2=$ regular; 3 = ruim. $\mathrm{SE}=$ frutos sem embalagem; $\mathrm{SP}=$ frutos acondicionados, individualmente, em saco plástico de polietileno; $\mathrm{SPP}=$ frutos acondicionados, individualmente, em saco plástico confeccionado com permanganato de potássio; $\mathrm{BA}=$ frutos acondicionados, individualmente, em bandeja de acetato; $\mathrm{BAP}=$ frutos acondicionados, individualmente, em bandeja de acetato transparente, contendo em seu interior sachê de permanganato de potássio; $\mathrm{CP}=$ frutos acondicionados em caixas de papelão, em grupos de $5 ; \mathrm{CPP}=$ frutos acondicionados em caixas de papelão, em grupos de 5, revestidas internamente com filme plástico aditivado com permanganato de potássio.

A firmeza é considerada um dos atributos de importância na qualidade de frutos, já que afeta a resistência ao transporte, às técnicas de conservação pós-colheita e ataque de microrganismos. Houve decréscimo da firmeza da polpa de $302,3 \mathrm{Kgf.cm}{ }^{-2}$ no tempo zero do armazenamento pós-colheita para
15,0 Kgf.cm ${ }^{-2}$, 42,7 Kgf.cm ${ }^{-2}$, 36,9 Kgf.cm ${ }^{-2}$, 41,5 Kgf.cm ${ }^{-2}, 44,4$ Kgf.cm ${ }^{-2}, 30,0 \quad \mathrm{Kgf.cm}^{-2}$ e $32,4 \mathrm{Kgf} . \mathrm{cm}^{-2}$, em 12 dias de armazenamento, respectivamente, nos tratamentos SE, SP, SPP, BA, BAP, CP e CPP (Figura 3).

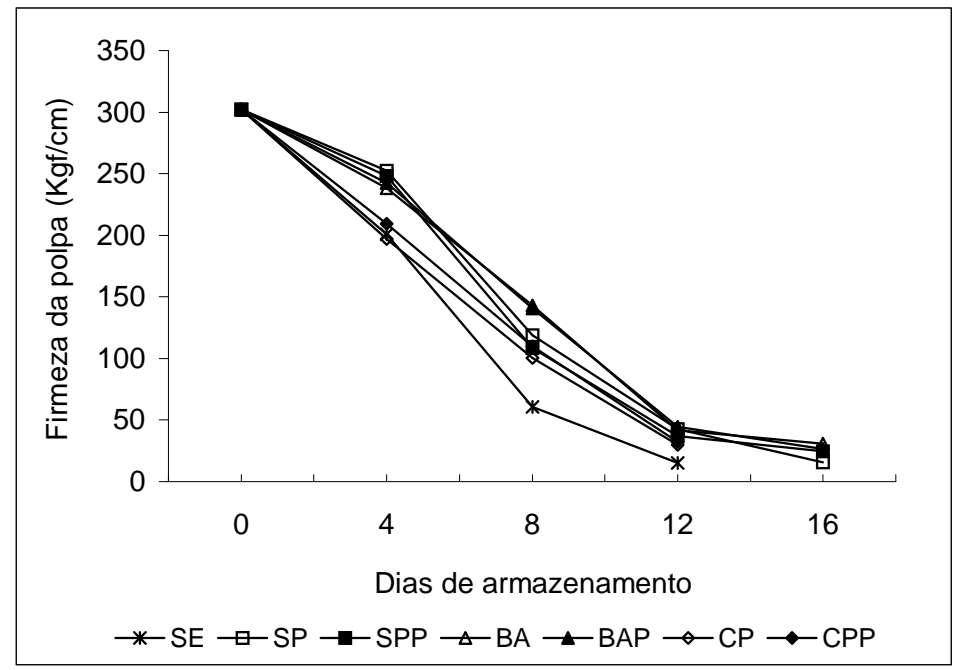

Figura 3. Firmeza da polpa em mangas 'Tommy Atkins', durante armazenamento a $24,4{ }^{\circ} \mathrm{C}, 70 \%$ UR. SE $=$ frutos sem embalagem; $\mathrm{SP}=$ frutos acondicionados, individualmente, em saco plástico de polietileno; $\mathrm{SPP}=$ frutos acondicionados, individualmente, em saco plástico confeccionado com permanganato de potássio; BA= frutos acondicionados, individualmente, em bandeja de acetato; $\mathrm{BAP}=$ frutos acondicionados, individualmente, em bandeja de acetato transparente, contendo em seu interior sachê de permanganato de potássio; $\mathrm{CP}=$ frutos acondicionados em caixas de papelão, em grupos de 5; $\mathrm{CPP}=$ frutos acondicionados em caixas de papelão, em grupos de 5, revestidas internamente com filme plástico aditivado com permanganato de potássio. 
Medlicott e Reynolds (1988) recomendam a colheita de mangas com a firmeza variando de 107,84 a $127,45 \mathrm{~N}$ e Alves et al. (2002) com firmeza de 129,41 N. Porém, a faixa adequada para a fruta ser consumida é variável conforme a preferência do consumidor e não foi encontrado em literatura indicações sobre a firmeza considerada boa para o consumo.

$\mathrm{O}$ uso de atmosfera modificada influenciou diretamente o amadurecimento dos frutos, e conseqüentemente, a perda de consistência da polpa. Verificou-se que houve diferença significativa entre os tratamentos e que os frutos em atmosfera modificada tiveram menor perda da firmeza da polpa durante o armazenamento, destacando-se o acondicionamento em embalagens individuais (BA, BAP, SP e SPP).

Em geral, as alterações na firmeza durante o amadurecimento resultam, predominantemente, da desestruturação da parede celular (TUCKER, 1993). Segundo este mesmo autor, o descréscimo da firmeza da polpa deve envolver uma interação complexa das atividades das enzimas amilásicas, pécticas e galactosidases com mudanças físico-químicas na parede.

Os teores de sólidos solúveis totais dos frutos são importantes tanto para o consumo in natura quanto para a indústria. Os frutos foram colhidos com 6,11 ${ }^{\circ}$ Brix e em todos os tratamentos ocorreu elevação dos teores de sólidos solúveis durante o armazenamento dos frutos, ao final do período de armazenamento, para $14,44^{\circ}$ Brix, $13,93{ }^{\circ}$ Brix, 7,92 ${ }^{\circ}$ Brix, $11,43{ }^{\circ}$ Brix, $11,463{ }^{\circ}$ Brix, 10,93 ${ }^{\circ}$ Brix e 14,94 ${ }^{\circ}$ Brix, respectivamente, nos tratamentos SE, SP, SPP, BA, BAP, CP e CPP (Tabela 1). Medlicott e Reynolds (1988) recomendam colher a manga com a teor de SST variando de 7 a $8^{\circ}$ Brix e Alves et al. (2002) com $7,3^{\circ}$ Brix, mas o valor para consumo deve estar entre 11 e $14^{\circ}$ Brix.

Nos frutos acondicionados nas caixas de papelão (CP e CPP) observa-se que ao final do período de armazenamento (12 dias) não ocorreu diferença numérica nos teores de sólidos solúveis, em relação ao tratamento controle (SE). Isto ocorreu devido ao material e à estrutura física da caixa de papelão, cujas laterais apresentavam furos, promovendo trocas gasosas que permitiram que os processos metabólicos de amadurecimento dos frutos ocorressem mais intensamente. Porém, os teores de sólidos solúveis destes tratamentos citados ( $\mathrm{SE} \mathrm{e} \mathrm{CP)}$ diferiram do CPP.

No tratamento SPP observa-se o efeito da atmosfera modificada, pois na condição de vácuo parcial estabelecido no momento do acondicionamento do fruto na embalagem SPP, ocorreu inibição do processo respiratório resultante do acúmulo de $\mathrm{CO}_{2}$ e diminuição do $\mathrm{O}_{2}$ no interior da 2005 (SOUZA et al., 2002). Neste caso, o retardo no amadurecimento foi devido ao efeito da atmosfera modificada.

Com o amadurecimento dos frutos ocorre a transformação das reservas acumuladas durante a formação e o desenvolvimento dos mesmos em açúcares solúveis (CHITARRA; CHITARRA, 2005). O uso de atmosfera modificada através da embalagem, influi na velocidade das reações de hidrólise dos carboidratos em açúcares, que foi lenta e gradativa. $\mathrm{O}$ mesmo processo foi verificado por Jeronimo e Kanesiro (2000) e Yamashita et al. (2001), na conservação e no amadurecimento de mangas.

Os teores de acidez titulável dos frutos no início do armazenamento foram de 1,088 $\mathrm{g}$ de ácido cítrico $100 \mathrm{~g}^{-1}$ de polpa (Tabela 2). Estes teores reduziram até ao final do armazenamento, mas variaram entre todos os tratamentos. A redução nestes teores também foi verificada por Jeronimo e Kanesiro (2000) durante o armazenamento de mangas 'Palmer'.

A perda da acidez é desejável em grande parte dos frutos e marcante no processo de amadurecimento. Kays (1991) afirma que após a colheita e durante o armazenamento, a concentração de ácidos orgânicos tende a declinar na maioria dos frutos, em conseqüência da larga utilização dessas substâncias como substrato respiratório e como esqueletos de carbono, para a síntese de novos compostos. 
Tabela 1. Teores de Sólidos Solúveis ( ${ }^{\circ}$ Brix), em mangas ‘Tommy Atkins’, durante armazenamento a $24,4{ }^{\circ} \mathrm{C}, 70 \%$ UR.

\begin{tabular}{cccccc}
\hline \multicolumn{5}{c}{ Período de armazenamento (dias) } \\
\hline Tratamentos $^{1}$ & 0 & 4 & 8 & 12 & 16 \\
\hline SE & $6,11 \mathrm{a}$ & $9,16 \mathrm{c}$ & $13,93 \mathrm{a}$ & $14,44 \mathrm{~b}$ & \\
SP & $6,11 \mathrm{a}$ & $7,35 \mathrm{~g}$ & $13,43 \mathrm{~b}$ & $13,93 \mathrm{c}$ & $15,04 \mathrm{a}$ \\
SPP & $6,11 \mathrm{a}$ & $7,85 \mathrm{f}$ & $5,92 \mathrm{e}$ & $7,92 \mathrm{f}$ & $11,93 \mathrm{~b}$ \\
BA & $6,11 \mathrm{a}$ & $9,36 \mathrm{~b}$ & $9,43 \mathrm{~d}$ & $11,43 \mathrm{~d}$ & $9,93 \mathrm{~d}$ \\
BAP & $6,11 \mathrm{a}$ & $8,86 \mathrm{~d}$ & $10,93 \mathrm{c}$ & $11,43 \mathrm{~d}$ & $11,43 \mathrm{c}$ \\
CP & $6,11 \mathrm{a}$ & $8,37 \mathrm{e}$ & $10,93 \mathrm{c}$ & $10,93 \mathrm{e}$ & \\
CPP & $6,11 \mathrm{a}$ & $11,86 \mathrm{a}$ & $13,94 \mathrm{a}$ & $14,94 \mathrm{a}$ & \\
\hline CV $^{2}$ & 0,08 & 0,08 & 0,06 & 0,09 & 0,05 \\
\hline
\end{tabular}

${ }^{1} \mathrm{SE}=$ frutos sem embalagem; $\mathrm{SP}=$ frutos acondicionados, individualmente, em saco plástico de polietileno; $\mathrm{SPP}=$ frutos acondicionados, individualmente, em saco plástico confeccionado com permanganato de potássio; BA= frutos acondicionados, individualmente, em bandeja de acetato; $\mathrm{BAP}=$ frutos acondicionados, individualmente, em bandeja de acetato transparente, contendo em seu interior sachê de permanganato de potássio; $\mathrm{CP}=$ frutos acondicionados em caixas de papelão, em grupos de $5 ; \mathrm{CPP}=$ frutos acondicionados em caixas de papelão, em grupos de 5, revestidas internamente com filme plástico aditivado com permanganato de potássio. ${ }^{2}$ Coeficiente de variação (\%). Médias seguidas pela mesma letra na coluna não diferem entre si pelo teste de Tukey, a 5\% de probabilidade.

Tabela 2. Teores de Acidez Titulável (g ácido cítrico . $100 \mathrm{~g}^{-1}$ ), em mangas 'Tommy Atkins', durante armazenamento a $24,4{ }^{\circ} \mathrm{C}, 70 \%$ UR.

\begin{tabular}{cccccc}
\hline \multicolumn{5}{c}{ Período de armazenamento (dias) } \\
\hline Tratamentos $^{1}$ & 0 & 4 & 8 & 12 & 16 \\
\hline SE & $1,088 \mathrm{a}$ & $0,765 \mathrm{f}$ & $0,249 \mathrm{e}$ & $0,111 \mathrm{f}$ & \\
SP & $1,088 \mathrm{a}$ & $0,570 \mathrm{~g}$ & $0,688 \mathrm{c}$ & $0,399 \mathrm{a}$ & $0,286 \mathrm{a}$ \\
SPP & $1,088 \mathrm{a}$ & $1,014 \mathrm{~b}$ & $0,856 \mathrm{~b}$ & $0,309 \mathrm{c}$ & $0,265 \mathrm{~b}$ \\
BA & $1,088 \mathrm{a}$ & $0,970 \mathrm{c}$ & $0,818 \mathrm{~b}$ & $0,330 \mathrm{~b}$ & $0,275 \mathrm{ab}$ \\
BAP & $1,088 \mathrm{a}$ & $0,887 \mathrm{e}$ & $0,651 \mathrm{c}$ & $0,108 \mathrm{f}$ & $0,121 \mathrm{c}$ \\
CP & $1,088 \mathrm{a}$ & $1,064 \mathrm{a}$ & $0,985 \mathrm{a}$ & $0,149 \mathrm{e}$ & \\
CPP & $1,088 \mathrm{a}$ & $0,944 \mathrm{~d}$ & $0,369 \mathrm{~d}$ & $0,172 \mathrm{~d}$ & \\
\hline $\mathrm{CV}^{2}$ & 0,46 & 0,33 & 2,69 & 2,12 & 2,11 \\
\hline
\end{tabular}

${ }^{1} \mathrm{SE}=$ frutos sem embalagem; $\mathrm{SP}=$ frutos acondicionados, individualmente, em saco plástico de polietileno; $\mathrm{SPP}=$ frutos acondicionados, individualmente, em saco plástico confeccionado com permanganato de potássio; $\mathrm{BA}=$ frutos acondicionados, individualmente, em bandeja de acetato; $\mathrm{BAP}=$ frutos acondicionados, individualmente, em bandeja de acetato transparente, contendo em seu interior sachê de permanganato de potássio; $\mathrm{CP}=$ frutos acondicionados em caixas de papelão, em grupos de 5; $\mathrm{CPP}=$ frutos acondicionados em caixas de papelão, em grupos de 5, revestidas internamente com filme plástico aditivado com permanganato de potássio. ${ }^{2}$ Coeficiente de variação (5). Médias seguidas pela mesma letra na coluna não diferem entre si pelo teste de Tukey, a $5 \%$ de probabilidade. 
O aumento nos teores de sólidos solúveis e a diminuição dos teores de acidez promoveu aumento na relação SS/AT durante o armazenamento e conseqüente amadurecimento dos frutos (Tabela 3). Para manga, segundo Medlicott e Reynolds (1988), o teor mínimo de SST varia de 7 a $8^{\circ}$ Brix e o teor máximo de ATT varia de 0,65 a $0,70 \%$ de ácido cítrico, resultando numa relação SST/ATT de 10,00 a 12,30.

Tabela 3. Relação Sólidos Solúveis/Acidez Titulável, em mangas ‘Tommy Atkins', durante armazenamento a 24,4 ㄷ, $70 \%$ UR.

\begin{tabular}{cccccc}
\hline \multicolumn{5}{c}{ Período de armazenamento (dias) } \\
\hline Tratamentos $^{1}$ & 0 & 4 & 8 & 12 & 16 \\
\hline SE & $5,215 \mathrm{a}$ & $11,982 \mathrm{c}$ & $55,884 \mathrm{a}$ & $13,017 \mathrm{a}$ & \\
SP & $5,215 \mathrm{a}$ & $12,899 \mathrm{a}$ & $19,553 \mathrm{c}$ & $34,97 \mathrm{e}$ & $52,680 \mathrm{~b}$ \\
SPP & $5,215 \mathrm{a}$ & $7,742 \mathrm{~g}$ & $6,918 \mathrm{f}$ & $25,632 \mathrm{f}$ & $45,012 \mathrm{c}$ \\
BA & $5,215 \mathrm{a}$ & $9,650 \mathrm{e}$ & $11,543 \mathrm{e}$ & $34,636 \mathrm{e}$ & $36,090 \mathrm{~d}$ \\
BAP & $5,215 \mathrm{a}$ & $9,995 \mathrm{~d}$ & $16,801 \mathrm{~d}$ & $105,81 \mathrm{~b}$ & $95,037 \mathrm{a}$ \\
CP & $5,215 \mathrm{a}$ & $7,866 \mathrm{f}$ & $11,099 \mathrm{e}$ & $73,429 \mathrm{~d}$ & \\
CPP & $5,215 \mathrm{a}$ & $12,562 \mathrm{~b}$ & $37,853 \mathrm{~b}$ & $91,887 \mathrm{c}$ & \\
\hline $\mathrm{CV}^{2}$ & 9,23 & 0,35 & 3,11 & 5,29 & 3,95 \\
\hline
\end{tabular}

${ }^{1} \mathrm{SE}=$ frutos sem embalagem; $\mathrm{SP}=$ frutos acondicionados, individualmente, em saco plástico de polietileno; $\mathrm{SPP}=$ frutos acondicionados, individualmente, em saco plástico confeccionadodo com permanganato de potássio; BA= frutos acondicionados, individualmente, em bandeja de acetato; $\mathrm{BAP}=$ frutos acondicionados, individualmente, em bandeja de acetato transparente, contendo em seu interior sachê de permanganato de potássio; $\mathrm{CP}=$ frutos acondicionados em caixas de papelão, em grupos de 5; $\mathrm{CPP}=$ frutos acondicionados em caixas de papelão, em grupos de 5, revestidas internamente com filme plástico aditivado com permanganato de potássio. ${ }^{2}$ Coeficiente de variação (\%). Médias seguidas pela mesma letra na coluna não diferem entre si pelo teste de Tukey, a 5\% de probabilidade.

A manga pode ser considerada uma razoável fonte de vitamina C. No Brasil, a ingestão diária recomendada para adultos é de 60,00 mg (BRASIL, 1998). Os teores de ácido ascórbico dos frutos no início do armazenamento foram de $32,37 \mathrm{mg} .100 \mathrm{~g} \mathrm{~g}^{-1}$ (Tabela 4). Estes teores reduziram em até cerca de $80 \%$ até ao final do armazenamento, conforme o amadurecimento dos frutos, mas variaram entre os tratamentos. A redução nos teores de ácido ascórbico também foi verificada por Cardello; Cardello (1998) e Yamashita et al. (2001), durante o amadurecimento de mangas 'Tommy Atkins'.
Os frutos acondicionados nas embalagens em saco polietileno de baixa densidade (SP e SPP) tiveram vida útil de 14 e 16 dias, respectivamente, mas durante o armazenamento ocorreu condensação de água na superfície interna destas embalagens, promovendo opacidade e dificuldade de visualizar o fruto. Ressalta-se ainda, que ao romper a embalagem de SPP, o aroma liberado era diferente do esperado para um fruto completamente maduro e propício para o consumo, pois lembrava um aroma semelhante ao de um produto fermentado, além de desagradável, indicando então, que houve problema de fermentação. Conseqüentemente, a atratividade do produto como um todo foi prejudicada. 
Tabela 4. Teores de Ácido Ascórbico (mg .100 g-1), em mangas ‘'Tommy Atkins', durante armazenamento a 24,4 ${ }^{\circ} \mathrm{C}, 70 \%$ UR.

\begin{tabular}{cccccc}
\hline \multicolumn{5}{c}{ Período de armazenamento (dias) } \\
\hline Tratamentos $^{1}$ & 0 & 4 & 8 & 12 & 16 \\
\hline SE & $32,37 \mathrm{a}$ & $24,59 \mathrm{~b}$ & $19,39 \mathrm{a}$ & $9,46 \mathrm{c}$ & \\
SP & $32,37 \mathrm{a}$ & $21,50 \mathrm{c}$ & $14,32 \mathrm{c}$ & $12,64 \mathrm{~b}$ & $8,56 \mathrm{~b}$ \\
SPP & $32,37 \mathrm{a}$ & $25,02 \mathrm{a}$ & $15,53 \mathrm{~b}$ & $13,06 \mathrm{a}$ & $6,55 \mathrm{~d}$ \\
BA & $32,37 \mathrm{a}$ & $16,69 \mathrm{~g}$ & $14,56 \mathrm{c}$ & $5,83 \mathrm{~g}$ & $7,34 \mathrm{c}$ \\
BAP & $32,37 \mathrm{a}$ & $20,59 \mathrm{~d}$ & $10,65 \mathrm{e}$ & $8,91 \mathrm{~d}$ & $9,69 \mathrm{a}$ \\
CP & $32,37 \mathrm{a}$ & $17,87 \mathrm{f}$ & $11,33 \mathrm{~d}$ & $8,06 \mathrm{e}$ & \\
CPP & $32,37 \mathrm{a}$ & $18,97 \mathrm{e}$ & $9,74 \mathrm{f}$ & $7,80 \mathrm{f}$ & \\
\hline CV $^{2}$ & 0,03 & 0,21 & 0,78 & 0,35 & 0,80 \\
\hline
\end{tabular}

${ }^{1} \mathrm{SE}=$ frutos sem embalagem; $\mathrm{SP}=$ frutos acondicionados, individualmente, em saco plástico de polietileno; $\mathrm{SPP}=$ frutos acondicionados, individualmente, em saco plástico confeccionado com permanganato de potássio; BA= frutos acondicionados, individualmente, em bandeja de acetato; $\mathrm{BAP}=$ frutos acondicionados, individualmente, em bandeja de acetato transparente, contendo em seu interior sachê de permanganato de potássio; $\mathrm{CP}=$ frutos acondicionados em caixas de papelão, em grupos de 5; $\mathrm{CPP}=$ frutos acondicionados em caixas de papelão, em grupos de 5, revestidas internamente com filme plástico aditivado com permanganato de potássio. ${ }^{2}$ Coeficiente de variação $(\%) ;{ }^{4}$ Final do tratamento. Médias seguidas pela mesma letra na coluna não diferem entre si pelo teste de Tukey, a 5\% de probabilidade.

\section{Conclusões}

Os melhores tratamentos de atmosfera modificada para manutenção dos frutos foram os de acondicionamento individual de manga em bandejas de acetato transparentes, recoberta com o filme de PVC esticável, com ou sem permanganato de potássio (BA e BAP), pois contribuíram para prolongar a conservação dos frutos em 4 dias, em relação ao controle (sem embalagem), em condições de temperatura ambiente (média de $24,4^{\circ} \mathrm{C}$ ). Porém, o permanganato de potássio na forma utilizada neste estudo (sachê preparado utilizando-se vermiculita como substrato, impregnada com $\mathrm{KMnO}_{4}$, na proporção de $10 \mathrm{~g} / 500 \mathrm{~g}$ de fruto) não interferiu nos resultados obtidos para a conservação dos frutos.

O uso da atmosfera modificada pela embalagem de frutos em sacos plásticos de polietileno de baixa densidade $25 \mu \mathrm{m}$ de parede simples (PE) confeccionado com permanganato de potássio não é recomendado, pois a baixa permeabilidade promoveu fermentação do fruto na embalagem ao final do período de armazenamento (16 dias), em condições de temperatura ambiente (média de $24,4{ }^{\circ} \mathrm{C}$ ).

\section{Agradecimentos}

À Fundação de Amparo à Pesquisa do Estado de São Paulo (FAPESP), pelo suporte financeiro.

\section{Referências}

AGRIANUAL 2005. Anuário da agricultura brasileira. São Paulo: FNP Consultoria \& Comércio, 2005. p.385-392.

ALVES, R.; ASSIS, J. S.; FILGUEIRAS, H. A. C.; MENEZES, J. B.; LIMA, M. A. C.; AMORIM, T. B. F.; MARTINS, A. G. Colheita e pós-colheita. In: GENÚ, P. J. C.; PINTO, A. C. Q. A cultura da mangueira. Brasília: Embrapa Informação Tecnológica, 2002. cap.17, p.381-405.

AWAD, M. Fisiologia pós-colheita de frutos. São Paulo: Nobel, 1993.

BANZATTO, D. A.; KRONKA, S. N. Experimentação agrícola. 3.ed. Jaboticabal: FUNEP, 1995.

BRASIL. Ministério do Meio Ambiente, dos Recursos Hídricos e da Amazônia Legal - MMA, Secretaria de Recursos Hídricos - SRH, Departamento de Aproveitamento Hidroagricola - DH. Manga Tommy Atkins. Brasília,DF, 1998. (Fruit Series, 2)

BRASIL. Portaria SVS/MS n.33, de 13 de janeiro de 1998. Tabelas de ingestão diária recomendada IDR. Diário Oficial da União, Brasília, 16 jan. 1998. p.1, Seção 1. 
BRUNINI, M. A.; OLIVEIRA, A. L.; SALANDINI, C. A. R.; BAZZO, F. R.. Influência de embalagens e temperaturas no armazenamento de jabuticabas (Myrciaria jabuticaba (Vell) Berg.) cv. 'Sabará'. Ciência e Tecnologia de Alimentos, Campinas, v.24, n.3, p.378-383, 2004.

CARDELLO, H. M. A. B.; CARDELLO, L. Teor de vitamina $\mathrm{C}$, atividade de ascorbato oxidase e perfil sensorial de manga (Mangifera indica L.) var. Haden, durante o amadurecimento. Ciência e Tecnologia de Alimentos, Campinas, v.18, n.2, p.211-217, 1998.

CHITARRA, M. I. F.; CHITARRA, A. B. Pós-colheita de frutos e hortaliças: fisiologia e manuseio. 2.ed. Lavras: UFLA, 2005.

CIA, P. Efeito da atmosfera modificada no controle de podridões pós-colheita e na qualidade de caqui cv. Fuyu. 2002. Dissertação (Mestrado em Agronomia) - Faculdade de Ciências Agronômicas, Universidade Estadual Paulista, Botucatu.

INSTITUTO ADOLFO LUTZ. Normas analíticas: método químico e físico para análise de alimentos. 2.ed. São Paulo: IAL, 1985. v.1.

JERONIMO, E. M.; KANESIRO, M. A. B. Efeito da associação de armazenamento sob refrigeração e atmosfera modificada na qualidade de mangas 'Palmer'. Revista Brasileira de Fruticultura, Jaboticabal, v.22, n.2, p.237243, 2000.

KAYS, J. S. Postharvest physiology of perishables plant products. New York: AVI, 1991.

KLUGE, R. A.; JORGE, R. Efeito da embalagem de polietileno na frigoconservação de ameixas amarelinhas. Revista Brasileira de Fruticultura, Cruz das Almas, v.231, n.3, p.21-25, 1992.

LABUZA, T. P.; BREENE, W. M. Applications of "active packaging" for improvement of shelf-life and nutritional quality of fresh and extended shelf-life foods. Journal of Food Processing and Preservation, Westport, v.13, n.1, p.1-69, 1989.
LIMA, L. C.; DIAS, M. S. C.; CASTRO, M. V.; MARTINS, R. N.; RIBEIRO JUNIOR, P. M.; SILVA, E. B. Conservação pós-colheita de figos verdes (Ficus carica L.) cv. roxo de Valinhos tratados com hipoclorito de sódio e armazenados sob refrigeração em atmosfera modificada passiva. Ciência e Agrotecnologia, Lavras, v.29, n.4, p.810-816, 2005.

MEDLICOTT, A. P.; REYNOLDS, S. B. Harvest maturity effects on mango fruit ripening. Tropical Agriculture, Trinidad, v.65, n.2, p.153-157, 1988.

PFAFFENBACH, L. B.; CASTRO, J. V.; CARVALHO, C. R. L.; ROSSETO, C. J. Efeito da atmosfera modificada e da refrigeração na conservação pós-colheita de manga espada vermelha. Revista Brasileira de Fruticultura, Jaboticabal, v.25, n.3, p.410-413, 2003.

SOUZA, J. P.; PRAÇA, E. F.; ALVES, R. E.; BEZERRA NETO, B.; DANTAS, F. F. Influência do armazenamento refrigerado em associação com atmosfera modificada por filmes plásticos na qualidade de mangas 'Tommy Atkins'. Revista Brasileira de Fruticultura, Jaboticabal, v.24, n.3, p.665-668, 2002.

TUCKER, G. A. Introduction. In: SEYMOUR, G. B.; TAYLOR, J. E.; TUCKER, G. A. Biochemistry of fruit ripening. London: Chapman \& Hall, 1993. p.1-51.

WAVHAL, K. N., ATHALE, P. W. Studies to prolong shelf life of mango. Acta Horticulture, Wagening, v.231, p.771$775,1989$.

YAMASHITA, F.; TONZAR, A. C.; FERNANDES, J. G.; MORIYA, S.; BENASSI, M. T. Embalagem individual de mangas cv. Tommy Atkins em filme plástico: efeito sobre a vida de prateleira. Revista Brasileira de Fruticultura, Jaboticabal, n.23, v.3, p.288-292, 2001.

ZAGORY, D. Ethylene-removing packaging. In: ROONEY, M. L. Active food packaging. Glasgow: Chapman \& Hall, 1995. p.38-54. 